\title{
Effect of forced expirations on mucus clearance in patients with chronic airflow obstruction: effect of lung recoil pressure
}

\begin{abstract}
C P van der Schans, D A Piers, H Beekhuis, G H Koëter, Th W van der Mark, D S Postma
\end{abstract}

\begin{abstract}
Spontaneous mucus clearance and the effect of forced expirations and coughing on mucus clearance were investigated in eight patients with chronic airflow obstruction and low elastic recoil pressure (emphysema group: mean FEV $145 \%$ predicted) and in seven patients with chronic airflow obstruction and normal elastic recoil pressure (chronic bronchitis group: mean FEV $157 \%$ predicted). Mucus clearance was measured in a central and a peripheral lung region by a radioactive aerosol tracer technique. Spontaneous mucus clearance from the peripheral lung region was higher in the patients with emphysema than in those with chronic bronchitis. There was no difference in central mucus clearance between the two groups. Mucus clearance from the peripheral lung region increased significantly during forced expirations and coughing in the patients with chronic bronchitis but not in those with emphysema. It is concluded that in patients with chronic airflow obstruction and regular sputum production spontaneous peripheral mucus clearance is greater in those with decreased elastic recoil pressure. Physiotherapy that includes forced expirations and coughing can enhance mucus clearance in such patients when elastic recoil pressure is normal but is unlikely to be effective when elastic recoil pressure is decreased.
\end{abstract}

\footnotetext{
Division of

Physiotherapy,

Department of

Rehabilitation

$C P$ van der Schans

Department of

Nuclear Medicine

D A Piers

H Beekhuis

Department of

Pulmonary Diseases

G H Koëter

Th W van der Mark

D S Postma

University Hospital, Groningen, The

Netherlands

Address for reprint requests: $C P$ van der Schans, Academisch Ziekenhuis, Academisch Ziekenhuis, secr. Fysiotherapie CMC Oostersingel 59, $9713 \mathrm{EZ}$ Groningen, The Netherlands.

Accepted 2 April 1990
}

Physiotherapy is commonly used to treat mucus retention in patients with chronic airflow obstruction. These patients often have increased mucus production in addition. Although retention of mucus is a complex problem and due to many different factors physiotherapy is usually given. The forced expiration technique, ${ }^{1-4}$ in which a forced expiration with an open glottis is carried out at different lung volumes, is commonly used in an attempt to mobilise mucus by providing a high expiratory axial airflow velocity in the airways. ${ }^{5-8}$

We wondered whether forced expirations were less useful in patients with mucus production who have decreased elastic recoil pressure than in patients with mucus production and normal elastic recoil pressure. The aim of the present study was to evaluate spontaneous mucus clearance, the effect of forced expirations with an open glottis at different lung volumes, and the effect of coughing in patients with sputum production. We studied two groups of patients with similar degrees of airways obstruction, one with normal elastic recoil pressure and the other with decreased elastic recoil pressure. For convenience we have labelled the two groups "chronic bronchitis" and "emphysema."

\section{Methods}

\section{MUCUS CLEARANCE MEASUREMENTS}

Mucus transport in the lungs was measured as described elsewhere. ${ }^{9}$ In summary, a radioactive aerosol was generated by means of an intermittent positive pressure respirator (Bennet AP-5); the nebuliser was filled with 35-50 MBq (1-1.5 mCi) technetium-99m labelled tin colloid (Amersham; $95 \%$ of the particles 1-15 $\mu \mathrm{m}$ ). In this way, a heterodisperse aerosol is produced and $10-15 \%$ of the tracer would be deposited in the airways after 40 inhalations. After inhaling the aerosol patients were asked to wash their mouth and drink water to clear their throat and oesophagus of radioactive tracer. The initial whole lung deposition pattern was quantified by expressing the amount of radioactive tracer in the central and peripheral regions as percentages of whole lung deposition. In each of the four studies the radiation dose to the lungs with this method is $0.6 \mathrm{mGy}(60 \mathrm{mrad})$ and the effective total body radiation dose $0 \cdot 1$ $\mathrm{mGy}(10 \mathrm{mrad}) .^{10}$

Clearance measurements were made with 
Figure 1 Example of a total lung region $(a)$; the peripheral region (b) is found by subtracting the central region (c) from the total lung region.
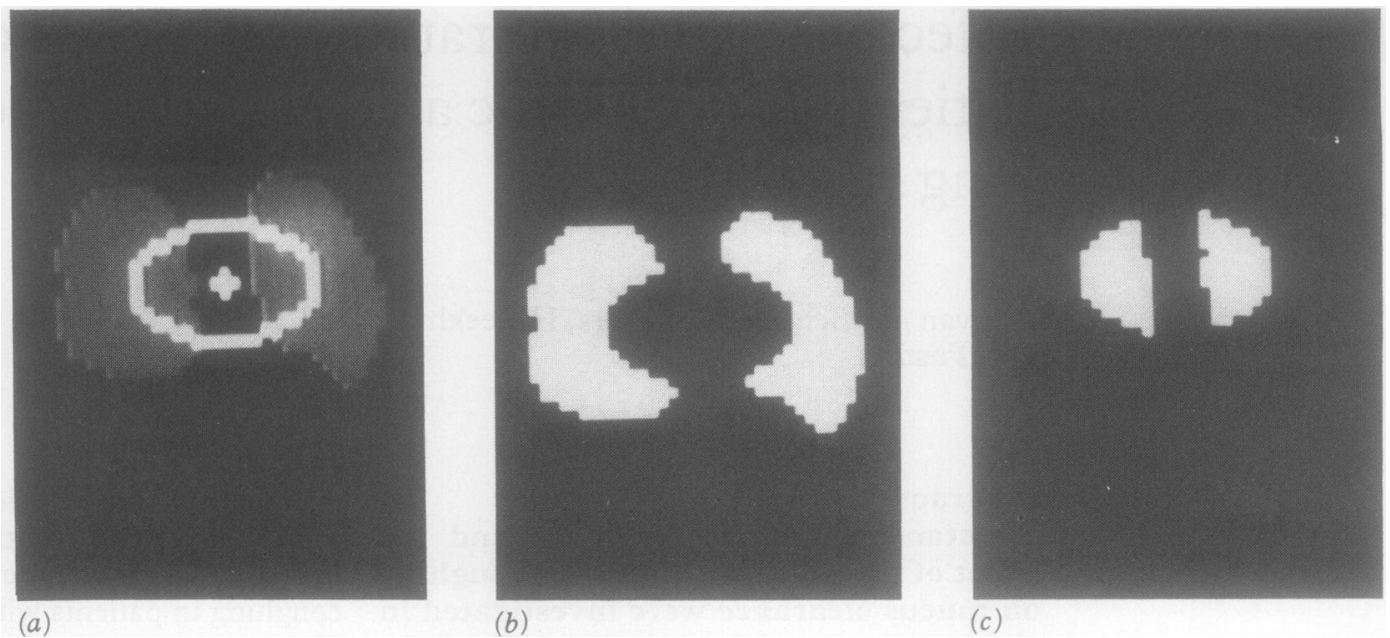

considered to reflect mucus transport in the lungs.

\section{PATIENTS}

Eight patients were selected on the entry visit on the basis of the following criteria and categorised as having emphysema: regular daily expectoration of mucus, airflow obstruction with an $\mathrm{FEV}_{1}$ below $80 \%$ predicted and values below predicted after bronchodilatation, static pulmonary compliance above $110 \%$ predicted, total lung capacity above $110 \%$ predicted or $\mathrm{FEV}_{1} / \mathrm{FIV}_{1}$ below $60 \%$, and circumstantial evidence of emphysema on the chest radiograph according to the criteria of Simon et al. ${ }^{11}$ Seven patients with chronic bronchitis were also selected on an entry visit. These patients had also regular daily expectoration of mucus, and an $\mathrm{FEV}_{1}$ below $80 \%$ predicted that was not fully reversible. They had to have a static lung compliance measurement below $90 \%$ predicted and had to show no clinical or radiological symptoms or signs suggesting emphysema. Spirometry was performed with a water sealed spirometer. Static lung volumes were assessed with a helium dilution technique. Pulmonary compliance was measured as outlined by Cotes. ${ }^{12}$ Each patient with emphysema was matched as closely as possible for $\mathrm{FEV}_{1}$ and smoking habits with a patient with chronic bronchitis. On the days of measurement the patients used their regular medication-that is, inhalation steroids, ipratropium bromide, theophylline, and beta agonists. Routine physiotherapy was not performed on the days of measurement. The study was approved by the medical ethics committee of the university hospital. All patients gave written, informed consent.

\section{PHYSIOTHERAPY}

Physiotherapy was always given by the same physiotherapist (C P vd S). The patients underwent three different physiotherapy protocols (II, III, IV) and one protocol without treatment (I) on four different days, always between 13.00 and 15.00 hours within nine days. Peak expiratory flow (PEF) was determined before each mucus clearance measurement. The highest value from three technically correct manoeuvres was taken for analysis.
Mucus clearance measurements were performed on each study day. The protocols were started after inhalation of the radiolabelled aerosol. After each protocol the patient was asked whether the treatment had been effective in clearing the lungs. None of the patients had used the forced expiration technique previously. During each protocol the patients were required to lie supine for 35 minutes. Protocols II, III, and IV were used in a randomised order; protocol I was carried out on the first study day. The four protocols were:

Protocol I This was used for control mucus clearance. No physiotherapy was performed.

Protocol II The patients breathed undisturbed for the first 10 minutes. Forced expirations with an open glottis were then performed from total lung capacity (TLC) every 30 seconds for a further 10 minutes. Patients then coughed as productively as possible every 30 seconds for five minutes. The last 10 minutes again consisted of undisturbed breathing.

Protocol III This was the same as II except that the forced expirations were now performed at functional residual capacity (FRC).

Protocol IV This consisted of 10 minutes of undisturbed breathing followed by a period of coughing every 30 seconds for 15 minutes. The patient then breathed again undisturbed for 10 minutes.

The patient took a drink of water to clear the oesophagus of radioactive tracer after the forced expiration periods and after the coughing period.

\section{STATISTICAL ANALYSIS}

Differences in radioactive tracer clearance at $10,20,25$, and 35 minutes after starting the clearance measurements were compared within the two groups by means of analysis of variance. Differences between the two groups were compared by means of Student's unpaired $t$ test. In both tests a significant difference was defined as $p<0.05$. All calculations were performed by using the SPSS statistical package. ${ }^{13}$ measurements and for measuring spontaneous 
Table 1 Characteristics of the patients

\begin{tabular}{|c|c|c|c|c|c|c|c|c|c|}
\hline Patient No: & 1 & 2 & 3 & 4 & 5 & 6 & 7 & 8 & $\begin{array}{l}\text { Mean } \\
\text { (SD) }\end{array}$ \\
\hline \multicolumn{10}{|l|}{ Emphysema } \\
\hline Age (y) & 69 & 64 & 66 & 61 & 60 & 63 & 69 & 34 & 61 (11) \\
\hline $\mathrm{FEV}_{1}$ (\% pred) & 44 & 35 & 72 & 66 & 45 & 33 & 38 & 30 & $45(16)$ \\
\hline $\mathrm{FEV}_{1}(\%$ VC) & 25 & 37 & 37 & 55 & 37 & 41 & 28 & 41 & 38 (9) \\
\hline FEV $_{1} /$ FIV $_{1}$ & 33 & 38 & 60 & 58 & 44 & 46 & 31 & 30 & 43 (12) \\
\hline TLC (\% pred) & 129 & 140 & 120 & 115 & 120 & 95 & 137 & 130 & $123(14)$ \\
\hline RV (\% pred) & 129 & 219 & 190 & 154 & 158 & 173 & 138 & 187 & $169(30)$ \\
\hline C (\% pred) & 141 & 167 & 180 & 125 & 190 & 110 & 110 & & $146(33)$ \\
\hline Sputum $(\mathbf{g})^{\star}$ & $10(2)$ & $19(3)$ & $68(5)$ & $4(1)$ & $53(2)$ & $12(3)$ & $4(1)$ & $13(2)$ & $24(24)$ \\
\hline Smoking $\dagger$ & & + & + & & - & + & - & - & \\
\hline Medication & S, I, B & $\mathrm{S}, \mathrm{I}, \mathrm{B}, \mathrm{T}$ & I & S, I, B & S, I, B & S, I & S, I, B, T & S, I, B, T & \\
\hline \multicolumn{10}{|l|}{ Bronchitis } \\
\hline Age (y) & 62 & 65 & 51 & 72 & 70 & & 43 & 64 & $61(10)$ \\
\hline $\mathrm{FEV}_{1}$ (\% pred) & 46 & 42 & 76 & 69 & 52 & & 35 & 81 & 57 (18) \\
\hline $\mathrm{FEV}_{1}(\% \mathrm{VC})$ & 54 & 32 & 55 & 70 & 46 & & 36 & 65 & $51(14) t$ \\
\hline $\mathrm{FEV}_{1} / \mathrm{FIV}_{1}$ & 44 & 45 & 63 & 68 & 50 & & 48 & 84 & $57(15) \ddagger$ \\
\hline TLC (\% pred) & 150 & 90 & 113 & 66 & 96 & & 109 & 100 & $103(26) \ddagger$ \\
\hline RV (\% pred) & 100 & 130 & 117 & 106 & 156 & & 200 & 120 & $133(35) \ddagger$ \\
\hline$C(\%$ pred $)$ & 70 & 76 & 89 & 90 & 54 & & 80 & 56 & $74(15) \ddagger$ \\
\hline Sputum $(\mathbf{g})^{\star}$ & $14(4)$ & $56(17)$ & $5(1)$ & $32(3)$ & 15( & & $4(2)$ & $16(1)$ & $20(18) \ddagger$ \\
\hline Smoking $†$ & + & + & & - & + & & + & - & \\
\hline Medication & S, I & S, I, B, T & S, I, T & S, B & S, I, & $3, \mathrm{~T}$ & S, I & $\mathrm{S}, \mathrm{I}, \mathrm{T}$ & \\
\hline
\end{tabular}

$\star$ Mean (SD) of the sputum production/day of three consecutive days.

$\dagger+$ Indicates smoker and - non-smoker or ex-smoker.

† Significant difference between patients with emphysema and those with bronchitis.

S-inhalation corticosteroid; I-ipratropium bromide; T-theophylline; B-beta agonist; VC-slow inspiratory vital capacity; $\mathrm{FEV}_{1} / \mathrm{FIV}_{1}$ - forced expiratory volume in one second as a percentage of the forced inspiratory volume in one second; TLC-total lung capacity; RV-residual volume; C-compliance.

Table 2 Mean (SD) peak expiratory flow (l/min) before the four different protocols

\begin{tabular}{lllllllll}
\hline Protocol & $I$ & & \multicolumn{1}{l}{$I I$} & & \multicolumn{1}{l}{ III } & \multicolumn{2}{l}{ IV } & \\
\hline Emphysema & 238 & $(80)$ & 263 & $(126)$ & 258 & $(110)$ & 237 & $(90)$ \\
Bronchitis & 251 & $(118)$ & 250 & $(90)$ & 249 & $(75)$ & 281 & $(101)$ \\
\hline
\end{tabular}

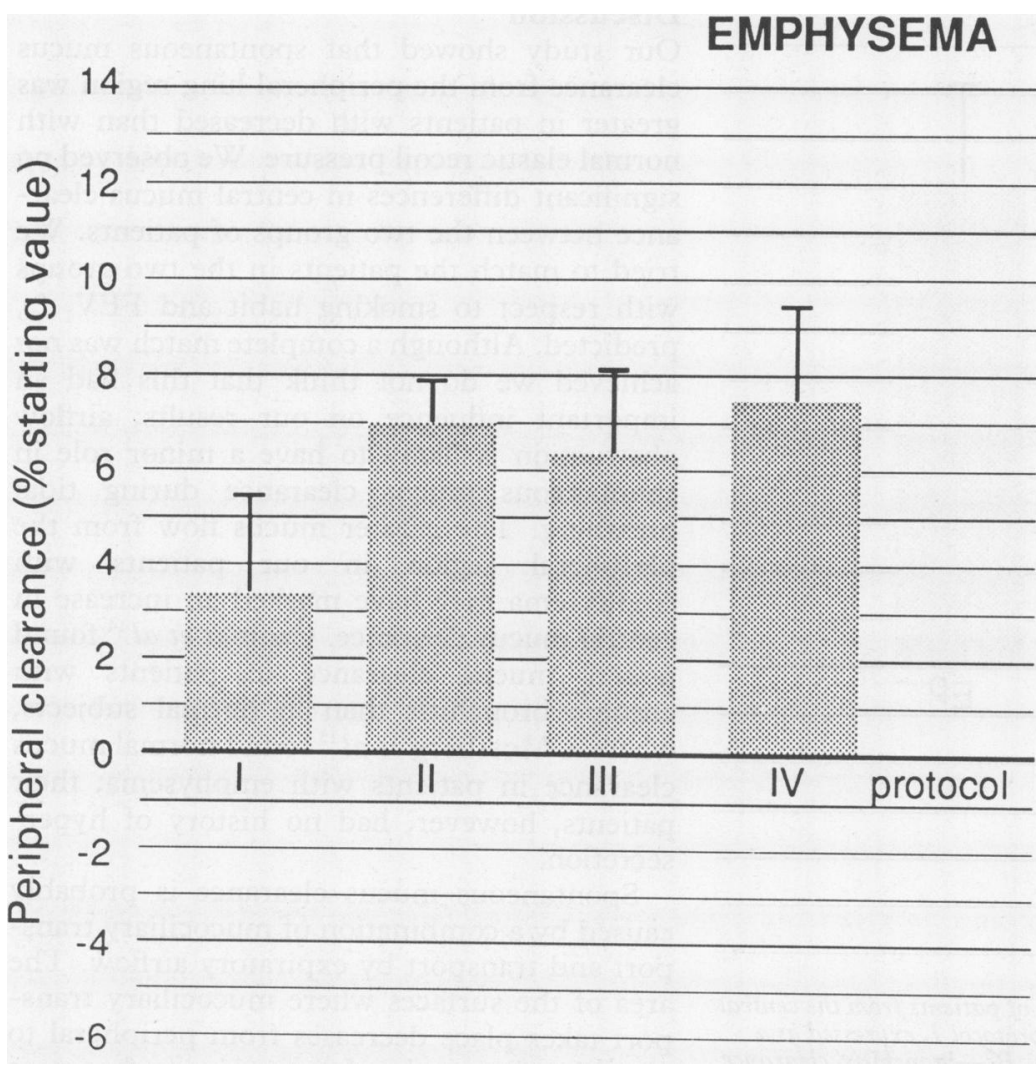

Figure 2 Clearance of the radioactive tracer in the patients with emphysema from the peripheral lung region in the period 10-20 minutes during the four different protocols, expressed as a percentage of the starting value (means and standard errors).

\section{Results}

The clinical characteristics of both groups of patients at the beginning of the study are given in table 1 . There were no significant differences between the two groups for age, $\mathrm{FEV}_{1}$, or sputum production. FEV $_{1} \%$ vital capacity (VC) and $F E V_{1} / F_{1}$ were lower in the groups with emphysema $(p<0.025, p<0.05)$. TLC (\% predicted), residual volume (RV; \% predicted) and compliance were higher in those with emphysema ( $p<0.05, p<0.05, p<0.0005)$. There was no significant difference in peak expiratory flow (PEF) values before the measurements on the four study days in either group of patients (table 2).

\section{DEPOSITION OF TRACER}

In the patients with chronic bronchitis the mean (SD) deposition of radioactive tracer in the central region on the four study days, expressed as a percentage of whole lung deposition, was 41 (4), 48 (11), 43 (8), and $45(4)$; peripheral deposition (\%) was 59 (4), 52 (11), 57 (8), and 55 (4). In the patients with emphysema central deposition was 39 (17), 39 (12), 40 (14), and 40 (11); the peripheral deposition was 61 (17), 61 (12), 60 (14), and 60 (11). The differences between the study days and between the two groups were not significant.

\section{MUCUS CLEARANCE}

Subjectively all patients thought that coughing was the only effective method of achieving mucus expectoration.

\section{Emphysema}

There was no significant difference in mucus clearance in either the central or the peripheral lung region between the four protocols at any 


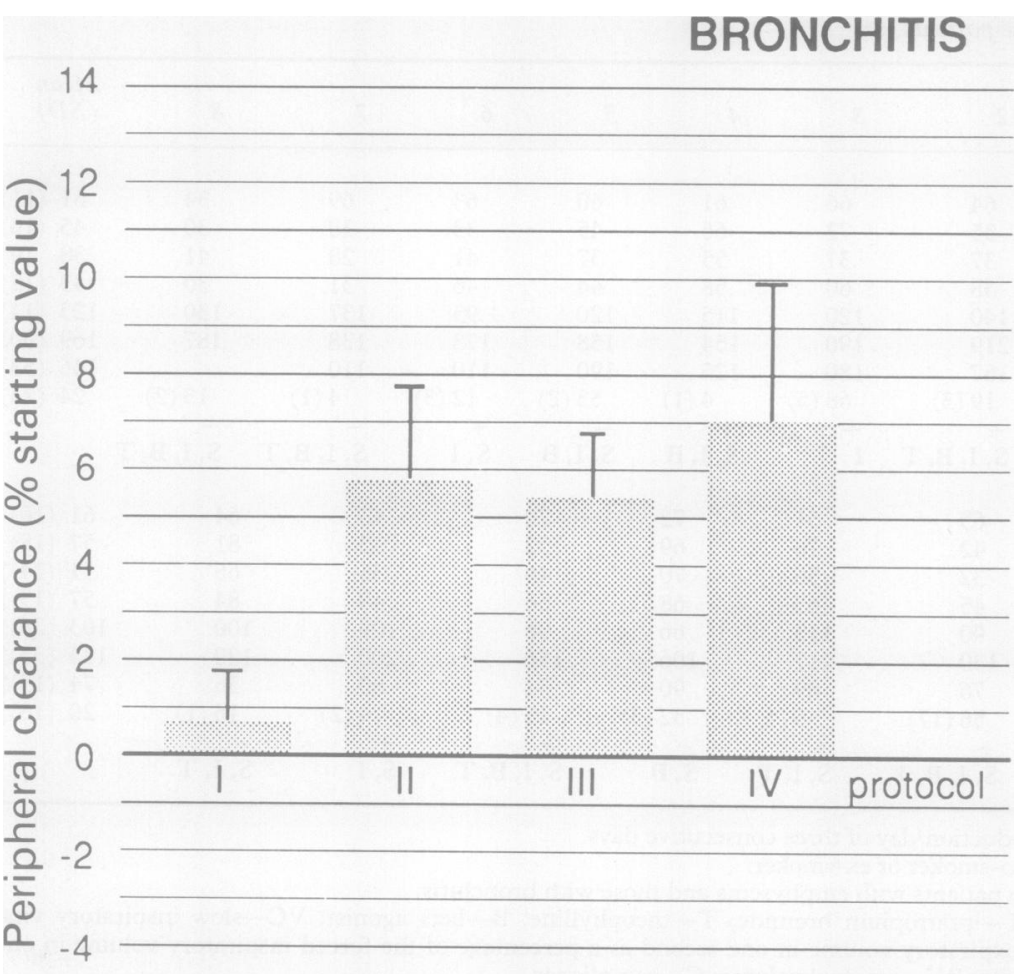

Figure 3 Clearance of the radioactive tracer in the patients with chronic bronchitis from the peripheral lung region in the period 10-20 minutes during the four different protocols, expressed as a percentage of the starting value (means and standard errors).

\section{PROTOCOL I}

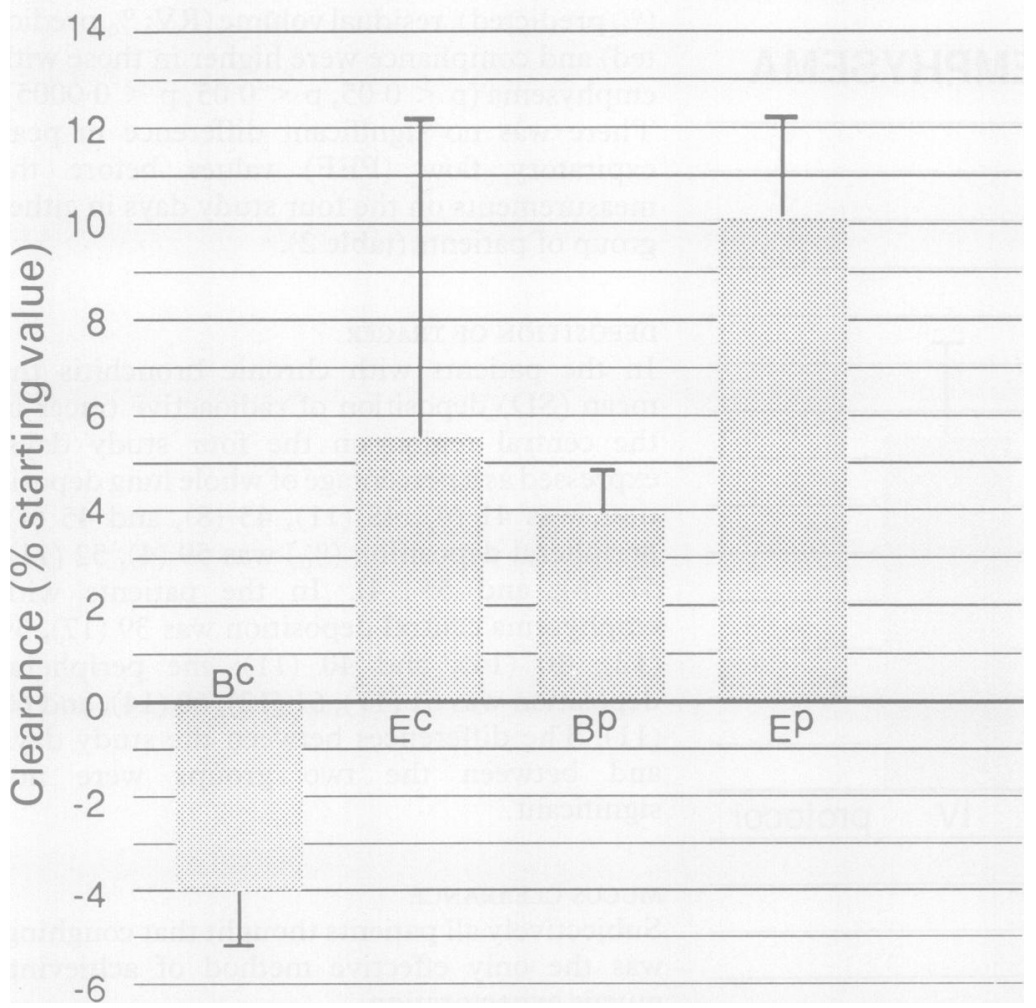

Figure 4 Clearance of the radioactive tracer in both groups of patients from the central and the peripheral region in the period 0-35 minutes during protocol $I$, expressed as a percentage of the starting value (means and standard errors). $B^{C}$-bronchitis, clearance from the central region; $E^{C}$-emphysema, clearance from the central region; $B^{P}$-bronchitis, clearance from the peripheral region; $E^{P}$-emphysema, clearance from the peripheral region. time (0-10, 10-20, 20-25, 25-35 minutes) (fig 2 ) or in the whole period (0-35 minutes).

\section{Chronic bronchitis}

There was no significant difference in peripheral mucus clearance between the four protocols in the period 0-10 minutes, when no physiotherapy was given. For the period 10-20 minutes peripheral mucus clearance during protocol I (control) was significantly lower than during the periods when forced expirations were performed at TLC (protocol II) or FRC (protocol III) or the patient was coughing (protocol IV) ( $p<0.05)$ (fig 3). Central mucus clearance during this period did not differ significantly between the four protocols. There were no significant differences in peripheral mucus clearance in the periods $20-25$ minutes or 25-35 minutes or in the whole period (0-35 minutes) between the four protocols.

No significant differences in central mucus clearance were observed between the four protocols.

Comparison of patients with emphysema and patients with chronic bronchitis

Spontaneous peripheral mucus clearance, as measured in protocol I over 35 minutes, was significantly higher in the patients with emphysema than in the patients with chronic bronchitis ( $p<0.005$ ); (fig 4). Central mucus clearance, however, was similar in the two groups during protocol I. There were no significant differences in peripheral or central mucus clearance between the two groups of patients for the other three protocols.

\section{Discussion}

Our study showed that spontaneous mucus clearance from the peripheral lung region was greater in patients with decreased than with normal elastic recoil pressure. We observed no significant differences in central mucus clearance between the two groups of patients. We tried to match the patients in the two groups with respect to smoking habit and $\mathrm{FEV}_{1} \%$ predicted. Although a complete match was not achieved we do not think that this had an important influence on our results; airflow obstruction is likely to have a minor role in spontaneous mucus clearance during tidal breathing. The greater mucus flow from the peripheral region in our patients with emphysema may have masked an increase in central mucus clearance. Camner et al ${ }^{14}$ found poorer mucus clearance in patients with chronic bronchitis than in normal subjects, whereas Mossberg et al ${ }^{15}$ found normal mucus clearance in patients with emphysema; their patients, however, had no history of hypersecretion.

Spontaneous mucus clearance is probably caused by a combination of mucociliary transport and transport by expiratory airflow. The area of the surfaces where mucociliary transport takes place decreases from peripheral to central airways; the decrease in surface area may be partly compensated for by a higher ciliary beat frequency in the central airways. ${ }^{16}$ 
Expiratory airflow during tidal breathing is more effective in clearing mucus when there is an increased thickness of the mucus layer. ${ }^{17}$ The mucociliary system may be more severely affected by the disease process in patients with chronic bronchitis than in those with emphysema, as a result of damaged cilia or changes in the rheological characteristics of the mucus.

Forced expirations increased peripheral mucus transport in the patients with normal or high elastic recoil pressure but had little effect in patients with low elastic recoil pressure, probably because of dynamic bronchial collapse during forced expiration in these patients. The increase in mucus clearance did not correlate with the initial $\mathrm{FEV}_{1} \%$ predicted $(r=0.03)$, so the differences in severity of airflow obstruction are unlikely to account for our results.

Mean mucus clearance was greater during coughing than during forced expirations but the differences were small and not statistically significant. These results contrast, however, with the patients' assessment, because all 15 thought coughing was the only effective method. During coughing the transpulmonary pressure is much higher than during a forced expiration with an open glottis ${ }^{18}$ and the energy cost is probably higher. Coughing did not, however, augment mucus transport when compared with forced expirations. Forced expirations are therefore to be preferred to coughing when additional measures have to be taken to treat mucus retention.

We observed no significant difference between forced expirations carried out at TLC and at FRC. The higher elastic recoil pressure during forced expiration at TLC does not apparently increase air flow velocity sufficiently to increase mucus transport to a greater extent than a forced expiration at FRC.

Several authors have suggested that physiotherapy is effective only when the mucus. expectoration is more than $30 \mathrm{ml}$ a day. ${ }^{19}$ Our study has shown that both forced expirations and coughing are also effective in patients who expectorate less. Expectoration of mucus may not lead to an improvement of lung function but it may contribute to the prevention of pulmonary infections.

In conclusion, mucus clearance was con- siderably less in our patients with chronic airflow obstruction and normal elastic recoil pressure than in patients with chronic airflow obstruction and decreased elastic recoil pressure. Forced expirations were less effective in treating retention of mucus in patients with low than with normal elastic recoil pressure.

We thank Professor Dr $\mathrm{H}$ J Sluiter for his critical advice; F Kampen-Bergsma, H C Touw, and W N A Beumkes for their help in preparing the manuscript; D J Buiter for making the illustrations; and $\mathrm{H}$ ter Veen for his assistance in analysing data on mucus clearance. This study was supported by a research grant from the Nederland Astma Fonds.

1 Pryor JA, Webber BA. An evaluation of the forced expiration technique as an adjunct to postural drainage. tion technique as an adjun

2 Pryor JA, Webber BA, Hodson ME, Batten JC. Evaluation of the forced expiration technique as an adjunct to postural drainage in treatment of cystic fibrosis. $B r$ Med J 1979 ; ii:417-8.

3 Sutton PP, Parker RA, Webber BA, et al. Assessment of the forced expiration technique, postural drainage and directed coughing in chest physiotherapy. Eur J Respir Dis 1983;64:62-8

4 Verboon JML, Bakker W, Sterk PJ. The value of the forced expiration technique with and without postural drainage in adults with cystic fibrosis. Eur J Respir Dis 1986; 69:169-74.

5 Leith DE. Cough. Physical Therapy 1968;48:439-47.

6 Clarke SW, Jones JG, Oliver DR. Resistance to two-phase gas-liquid flow in airways. J Appl Physiol 1970;29:464-71.

7 Dawson SV, Elliott EA. Wave-speed limitation on expiratory flow-a unifying concept. J Appl Physiol 1977;43 498-515.

8 Mead J, Turner JM, Macklem PT, Little JB. Significance of the relationship between lung recoil and maximum expiratory flow. J Appl Physiol 1967;22:95-108.

9 Schans CP van der, Piers DA, Postma DS. Effect of manual percussion on tracheobronchial clearance in patients with chronic airflow obstruction and excessive tracheobronchial secretion. Thorax 1986;41:448-52.

10 Prato FS, Vinitski S. Radiation dose calculations for inhalation of Tc-99m sulfur colloid radioaerosol. J Nucl Med 1983;24:816-21.

11 Simon G, Pride NB, Jones NL, Raimondi AC. Relation between abnormalities in the chest radiograph and changes in pulmonary function in chronic bronchitis and emphysema. Thorax 1973;28:15-23.

12 Cotes JE. Lung function: principles and application in medicine. Oxford: Blackwell, 1979.

13 Nie NH. SPSS statistical package for the social sciences second edition. New York: McGraw-Hill, 1975.

14 Camner P, Mossberg B, Philipson K. Tracheobronchial clearance and chronic obstructive lung disease. Scand $J$ clearance and chronic obst
Respir Dis 1973;54:272-81.

15 Mossberg B, Philipson K, Camner P. Tracheobronchial clearance in patients with emphysema associated with alpha 1 -antitrypsin deficiency. Scand J Respir Dis 1978 59:1-7.

16 Rutland J, Griffin WM, Cole PJ. Human ciliary beat frequency in epithelium from intrathoracic and extrathoracic airways. Am Rev Respir Dis 1982;125:100-5.

$17 \mathrm{Kim}$ CS, Rodriguez CR, Eldridge MA, Sackner MA. Criteria for mucus transport in the airways by two-phase Criteria for mucus transport in the airways by two-phase
gas-liquid flow mechanism. J Appl Physiol 1986;60:901-7.

18 Langlands J. The dynamics of cough in health and in chronic bronchitis. Thorax 1967;22:88-96.

19 Kiriloff LH, Owens GR, Rogers RM, Mazzocco MG. Does chest physical therapy work? Chest 1985;88:436-44. 